\title{
Retinopathy of prematurity in a tertiary care hospital: incidence and risk factors
}

\author{
Reddy B ${ }^{1}$, Doddamani R.M², Koujalagi M.B ${ }^{3}$, Guruprasad G ${ }^{4}$, Ashwini R.C ${ }^{5}$, Aradya G.H ${ }^{6}$, Raghoji C ${ }^{7}$ \\ ${ }^{1}$ Dr Bharath Reddy, Senior Resident, ${ }^{2}$ Dr Raghavendra M Doddamani, Assistant Professor, ${ }^{3}$ Dr M.B. Koujalagi, \\ Professor, ${ }^{4}$ Dr Guruprasad G, Professor, ${ }^{5}$ Dr Ashwini R C, Assistant Professor, ${ }^{6}$ Dr Gayathri H Aradya, Fellow in \\ Neonatology, ${ }^{7}$ Dr Chaithali Raghoji, Senior Resident. All authors affiliated with Department of Neonatology, Bapuji \\ Child Health Institute, Davangere, India.
}

Address for Corresponding: Dr Raghavendra M Doddamani, Assistant Professor, Department of Paediatrics, J.J.M. Medical College, Davangere. Email Id: rags_md@yahoo.co.in

\begin{abstract}
Objective: To study the incidence and risk factors predisposing to retinopathy of prematurity (ROP) in Bapuji child Health Institute NICU. Design: Prospective cohort observational study. Setting: Infants admitted to a neonatal intensive care unit of Bapuji child Health Institute NICU in a period of two years. Methods: Preterm infants with birth weight < $1500 \mathrm{~g}$ and gestation $<34$ weeks were screened for ROP at 4 weeks after birth or 31-33 weeks post conceptional age, whichever was later. Infants with birth weight $>1500 \mathrm{~g}$ and gestation $>34$ weeks were screened only if they had additional risk factors. Those found to have high risk ROP had laser photocoagulation. Results: The incidence of ROP in the 200 infants who were screened was $13.5 \%$. No ROP was found in infants weighing $>2000 \mathrm{~g}$ or with a gestational age more than 36weeks. Risk factors predisposing to ROP were oxygen therapy $(P=0.04)$, apnea [ $\mathrm{p}=0.001]$, ventilation [0.001], anemia [0.001], blood and blood product transfusion [0.001 ]. Conclusion: One third of the infants with ROP needed laser photo coagulation, the outcome of which was good. Risk factors predisposing to ROP were oxygen therapy, apnea, ventilation, blood transfusion, exchange transfusion.
\end{abstract}

Key words: Birth weight, Gestational age, Oxygen therapy, Prematurity, ROP.

\section{Introduction}

Retinopathy of prematurity (ROP) is a disorder of the developing retinal blood vessels in the premature infant retina. The key pathological change in ROP is peripheral retinal neovascularisation. This may regress completely or leave sequel from mild myopia to bilateral total blindness. Severe retinopathy of prematurity (ROP) can lead to retinal detachment and permanent visual loss. As acute ROP worsens, characteristic changes occur in the blood vessels of the posterior retina. Plus disease is considered to be present when the vascular changes are so marked that the posterior veins are dilated and the arterioles tortuous [1].

The condition was first described by Terry in 1942 as retrolentalfibroplasia [2]. As developing countries

Manuscript received: $24^{\text {th }}$ April 2016

Reviewed: $5^{\text {th }}$ May 2016

Author Corrected; $18^{\text {th }}$ May 2016

Accepted for Publication: $31^{\text {st }}$ May 2016 began to adopt modern neonatology techniques in the 1980s and 1990s, increasing the survival of preterm neonates, ROP began to emerge in middle-income countries (the 'third epidemic'), where it can account for as much as $60 \%$ of childhood blindness [3].

The 'first epidemic' of ROP took place in the 1940s and 1950s, affected larger premature infants, and was associated with unmonitored oxygen supplementation $[3,4]$. In India, with the development of neonatal intensive care units, premature infants with extremely low birth weights are surviving and are at highest risk of developing ROP [5].

Over $22 \%$ of childhood blindness in India is attributable to Retinal etiologies and "Retinopathy of PrematurityROP" is the commonest, and more preventable of these causes. The incidence of ROP in India estimated to be $47.27 \%$ according to Charan R et.al [6]. 
The control of blindness in children is considered a high priority within the World Health Organization's (WHO's) VISION 2020- The Right to Sight programme [7]. Data on childhood blindness in India are incomplete, but applying an estimated prevalence of 0.7 $( \pm 0.3)$ per 1000 children to the under-16 population provides an estimate of $218000( \pm 92000)$ blind children [8].

Retinopathy of prematurity (ROP) is an important cause of preventable blindness in children [9]. This study intends to determine the incidence and risk factors of ROP in level 3 neonatal care centre.

\section{Methodology}

Study was carried out in a period of two years. A total of 200 babies were screened in the present study. Babies of gestational age $\leq 34$ weeks and birth weight $\leq$ 1500 gms OR babies of birth weight between $>1500 \mathrm{gms}$ or $>34$ weeks with other risk factors like Oxygen therapy, Ventilation, Exchange Transfusion, Blood products use, Hyperbilirubinemia, Apnea, Septicemia, CPAP admitted to Bapuji Child Health Institute and Research Centre NICU, Davangere were taken as source of data. Babies born at > 34 weeks of gestational age and $>1500 \mathrm{gms}$ without risk factors were excluded from the study.

Ethical clearance was obtained from the hospital ethics committee and informed consent of the parents was also obtained.
Method of Examination: All the babies were screened with RETCAM by expert ophthalmic technician. The initial examination was carried out at 4 weeks after birth or 31 to 33 weeks post-conceptional age, whichever was later.

A detailed history including birth weight, gestational age at birth, weight for gestation, problems during NICU stay and its management were recorded in a prestructured proforma. The screening was done in NICU nursery under the guidance of the neonatologist. The baby was clothed and mummified and was fed and burped one hour prior to examination. Incubator dependent babies can be screened (and even treated) within the incubator itself through the slanting wall without disturbing the equilibrium of the infant.

The screening was done using RETCAM. Eyes were examined with an infant speculum, under topical anesthesia using 2\% Proparacaine drops. The pupils were dilated by using $0.4 \%$ Tropicamide $+1.25 \%$ Phenylepherine eye drops two or three times, till full dilatation occurred. Retinopathy was graded into stages and zones as per the ICROP classification. Infants with normal vascularization up to the periphery were not examined again. Those with ROP were examined every week till regression occurred or till they reached threshold for laser treatment.

Statistical analysis: Analysis was performed using SPSS version 10.0. Univariate analysis was conducted using Chi square test.

\section{Results}

In the present study out of 200 cases 27 cases were ROP positive and majority of cases of ROP occurred between 28 -30 weeks $(n=12,24.5 \%)$ of gestation. In 31-33 weeks of gestation $10(11.6 \%)$ cases were seen. In 34-36 weeks of gestation 5 cases $(7.5 \%)$ of ROP were seen. As the gestational age decreased there is significant increase $(\mathrm{p}>0.03)$ in the incidence of ROP.

$40 \%$ of cases between 740-1000 gm of birth weight developed ROP. 15.7\% of newborns between 1000-1500 gm of birth weight developed ROP. $10.3 \%$ of newborns between 1500-2000 gm of birth weight developed ROP. No baby with birth weight > 2000gm developed ROP. 18 newborns had birth weight less than 1500 out of total 27 newborns with ROP. 9 newborns had birth weight $>1500$ (table 1$)$.

In 27 ROP positive newborns there were 18 male newborns and 9 female newborns. There was no significant difference in the distribution of ROP between male and female sex. In the study out of 160 newborns who received oxygen, $16.3 \%$ $(n=26)$ of newborns developed ROP. $2.5 \%(n=1)$ newborns who have not received oxygen developed ROP. In the present study there was a significance association of ROP with oxygen therapy with a p value of 0.04 (table 2).

$13(6.5 \%)$ out of 200 cases had apnea. Out of 13 cases 10 (76.9\%) had ROP. In 27 ROP positive cases $10(37.03 \%)$ had apnea. In this study highly significant association between apnea and ROP is seen (p value $<0.001) .8(4.0 \%)$ out of 200 
newborns received ventilation in which $6(75 \%)$ had ROP. Out of 27 ROP positive cases $6(22.2 \%)$ received ventilation (table 3). There is a highly significant association between ventilation and ROP with a $\mathrm{p}$ value of $<0.001$.

16 newborns (8.0\%) out of 200 had anemia. Out of 16 newborns 15 (93.8\%) developed ROP. Out of 27 ROP positive newborns $15(55.5 \%)$ were found to be anemia (table 3$)$. There is a highly significant association between anemia and ROP In the present study with a $\mathrm{p}$ value of $<0.001$.

15 newborns (7.5\%) received blood and blood product transfusion. Out of 15 newborns 13 newborns (86.7\%) developed ROP. Out of 27 ROP positive cases 13 newborns (48.1\%) developed ROP. There is a highly significant association between both the variables with a $\mathrm{p}$ value of $<0.001$. Out of 200 newborns 10 newborns $(5 \%)$ received exchange transfusion in which 6 newborns $(60 \%)$ developed ROP. In total of 27 ROP positive cases 6 cases $(22.2 \%)$ have received exchange transfusion (table 3). There is a highly significant association between exchange transfusion and ROP.

Table-1: Birth weight and ROP.

\begin{tabular}{|c|c|c|c|c|c|c|}
\hline & \multicolumn{2}{|c|}{ Positive } & \multicolumn{2}{c|}{ Negative } & \multicolumn{2}{c|}{ Total } \\
\hline Birth Weight(gm) & No. & \% & No. & $\%$ & No. & \% \\
\hline $740-1000$ & 2 & 40.0 & 3 & 60.0 & 5 & 51 \\
\hline $1000-1500$ & 16 & 15.7 & 86 & 84.3 & 102 & 43.5 \\
\hline $1500-2000$ & 9 & 10.3 & 78 & 89.7 & 87 & 3.0 \\
\hline $2000-2500$ & 0 & 0.0 & 6 & 100.0 & 6 & 100.0 \\
\hline Total & 27 & 13.5 & 173 & 86.5 & 200 & \\
\hline
\end{tabular}

Table-2 - Oxygen Therapy and ROP Outcome.

\begin{tabular}{|c|c|c|c|c|c|c|}
\hline \multirow{2}{*}{ Oxygen } & \multicolumn{2}{|c|}{ Positive } & \multicolumn{2}{c|}{ Negative } & \multicolumn{2}{c|}{ Total } \\
\cline { 2 - 7 } & No. & \% & No. & \% & No. & \% \\
\hline Given & 26 & 16.3 & 134 & 83.8 & 160 & 78.0 \\
\hline Not given & 1 & 2.5 & 39 & 97.5 & 40 & 22.0 \\
\hline Total & 27 & 13.5 & 173 & 86.5 & 200 & 100.0 \\
\hline
\end{tabular}

Table 3- Correlation between Apnea, Anemia and Blood or Blood Product Transfusion and ROP.

\begin{tabular}{|c|c|c|c|c|c|c|c|c|c|c|c|c|}
\hline \multirow[t]{2}{*}{ ROP } & \multicolumn{4}{|c|}{ Apnea } & \multicolumn{4}{|c|}{ Anemia } & \multicolumn{4}{|c|}{ Blood transfusion } \\
\hline & Present & $\%$ & Absent & $\%$ & Present & $\%$ & Absent & $\%$ & Present & $\%$ & Absent & $\%$ \\
\hline Positive & 10 & 76.9 & 17 & 9.1 & 15 & 93.8 & 12 & 6.5 & 13 & 86.7 & 14 & 7.6 \\
\hline Negative & 3 & 23.1 & 170 & 90.9 & 1 & 6.3 & 172 & 93.5 & 2 & 13.3 & 171 & 92.4 \\
\hline Total & \multicolumn{2}{|c|}{13} & \multicolumn{2}{|c|}{$\begin{array}{l}1 \\
177\end{array}$} & \multicolumn{2}{|c|}{16} & \multicolumn{2}{|c|}{184} & \multicolumn{2}{|c|}{15} & \multicolumn{2}{|c|}{185} \\
\hline
\end{tabular}

\section{Discussion}

Retinopathy of prematurity, first identified by Terry $[2,10]$ in 1942 , within a decade became the largest cause of childhood blindness in the United States [3] and a major cause of blindness throughout the technologically developed world. Terry's original reports designated the condition retrolental fibroplasia (RLF) on the basis of his impression that the primary change involved a proliferation of the embryonic hyaloids system that incorporated the retina. Owens and Owens [11] found that the hyaloids system was normal at birth and that RLF developed postnatally [11]. As the pathogenesis and clinical spectrum of manifestations became better understood, the term retinopathy of prematurity was generally adopted.

The discovery of the relationship between supplementary oxygen and ROP in the 1950 $[12,13,14,15]$ led to the practice of rigid curtailment of oxygen supplementation in the nursery, and a dramatic decrease in the incidence of ROP followed.

Our understanding of vascular development has advanced recently, both in general and with respect of the retinal circulation [16]. As a rule retinal vasculature 
develops to meet retinal metabolic demand, with the exception of the foveal region, which has a very different vascular pattern [16], so that very early in development when the retina is thin it receives all its nutrients from the underlying choroid. The choroid is vascularized from about 6 weeks gestational age (GA) [17], but with increasing neural density and retinal thickness, the choroidal circulation alone cannot meet all the needs of the retina and a separate retinal circulation is required. Consequently at 14-15 weeks of gestation, retinal vascularization commences. This comprises two main- processes: vasculogenesis and angiogenesis [16]. Newly formed capillaries remodel and form a mature retinal vascular network with capillary-free areas [18], which in modern parlance indicates that retinal tissue responds to excess or lack of oxygen by trimming or inducing growth in its microvasculature so that oxygen supply matches the metabolic requirements of the retina [19].

Incidence of ROP In the presentstudy is $13.5 \%$. The incidence of ROP in the west has been reported to be $53-88.5 \%$ in babies with birth weight $<1000 \mathrm{gm}$ and $34.9-60.1 \%$ in $<1500 \mathrm{gm}$ babies. In the presentstudy the incidence seems to be higher in 28 to 30 weeks group. The incidence of ROP in other Indian studies range from $11.9 \%$ to $52 \%$. In a study done by Sharma P et. al, (2009) [20] the incidence was $11.9 \%$ In other studies by Chaudhari S et.al,(2009) [21] and Varugheses (2001) et.al, [22], the incidence rates were $22.3 \%, 52 \%$ respectively.

The major ROP risk factor is the degree of immaturity as measured by either birth weight or GA. Although these two parameters are highly correlated, this relationship is not linear as in intrauterine growth retardation. Furthermore, the assessment of GA, especially for the most immature neonate is prone to inaccuracy. As stated earlier both the incidence and severity of ROP are inversely related to birth weight and GA $[23,24]$ with the first being the more powerful predictor $[25,26]$.

In the present study the incidence of ROP is $13.5 \%$ in ELBW $(<1000 \mathrm{gm})$ babies the incidence is $40 \%$. In babies with birth weight $1000-1500 \mathrm{gm}$ the incidence is $15.7 \%$. In babies with birth weight between 1500 to $2000 \mathrm{gm}$ the incidence is $10.3 \%$. In the present study, we would have missed 15 cases of ROP if we had used<30weeks criteria, as per American Academy of Pediatrics (AAP) updated recommendations. In western studies [20], the incidence of ROP has been reported to be $53-88.5 \%$ in $<1000 \mathrm{gm}$ babies and 34.9 to $60.1 \%$ in $<1500$ gm babies. In a study done by Vinekar et. al, $45 \%$ of the babies had threshold ROP at $>1250 \mathrm{gm}$ birth weight [27]. There is a geographic variation in the incidence of ROP in babies born at even similar gestational ages. In the west ROP, at least the threshold variety is not seen in higher birth weight babies. In contrast ROP is seen in larger, bigger birth weight babies in Asia and other developing countries. In south India, threshold ROP has been seen in babies born with $2000 \mathrm{~g}$ birth weight. While partly this might reflect the failure of very small infants to thrive, other factors such as perhaps the quality of neonatal care that has led to a decline of ROP in the West is lacking here. Of note, a similar scenario existed in Lithuania, wherein ROP was seen in larger infants initially. However, the birth weights of babies with ROP have fallen quickly due to improvements in neonatal care. A similar swing in the pendulum could be expected to occur in India as well! Nevertheless, it is essential to realize that at least in the present scenario, the cutoff birth weight and the gestational ages of our babies that need to be screened for ROP need to be higher. In a study done by Chaudhary et.al [20], the incidence of ROP in 58 ELBW infants was $36.2 \%$, in the 381 VLBW infants, it was $23.6 \%$ and was $11.4 \%$ in 105 infants weighing $1500-1999 \mathrm{~g}$. No ROP was seen in infants with birth weight $\geq 2000 \mathrm{~g}$ and gestational age more than 36 weeks.

In the present study the incidence of ROP in babies with gestational age $\leq 36$ weeks is $3.5 \%$. Incidence increased as the gestational age decreased. Prematurity is the single most important risk factor responsible for retinopathy of prematurity. As reported by Palmer, et.al, [20], incidence and severity of ROP was closely related to lower birth weight and lower post-conceptional age, as was seen in the present study. In a study done by Chaudhari S, et.al, the Incidence was $83 \%$ in $28-30$ weeks, $32 \%$ in $31-33$ weeks, and $13 \%$ in $33-36$ weeks [20].

Campbell was the first to suggest that supplemental oxygen was the cause for the sudden increase in the numbers of infants developing RLF in the early 1940s. Saito et.al,.'s conclusion that extremely premature infants with fluctuating arterial oxygen probably have a higher risk of developing progressive ROP [28]. It was confirmed by Cunningham et.al, [29] and York et.al,. [30]. Clinical implication from these four studies is that, with respect to ROP development, arterial oxygen levels are particularly critical within the first weeks after birth (probably 4-6 weeks). ROP may develop in 
preterm infants who have never received oxygen and in premature infants with cyanotic heart-disease. Furthermore, some studies have suggested a relationship between neonatal hypoxia and R0P [31] and in an animal model retinal ischemia may lead to the same retinal changes as hyperoxia [32].

In the present study prolonged oxygen therapy was found to be a significant risk factor $[\mathrm{p}=0.04]$. It is found that mean duration of oxygen was significantly higher in the ROP group. Study done by Rekha S et. al, [33] also have shown a similar significance with the duration of oxygen therapy. In a studies done by Chaudhari S et.al, [20], Gupta VP et. al, [34] oxygen was found to be significantly associated with ROP. Study done by Dutta S et. al, [35] has concluded that there was no significant association of ROP with oxygen therapy.

In the present study apnea found to be significant risk factor. [ $\mathrm{p}=<0.001]$. In a study done by AgarwalR $^{15}$, et.al, in 2002 apnea came as a significant risk factor. In another study by Gupta VP et.al, [34] in 2004 apnea came as a significant risk factor. In another study by Chaudhary S et.al,[20] in 2009 apnea came as a significant risk factor. In the present study ventilation found to be highly significant risk factor $[\mathrm{p}=<0.001]$. In a study done in Iran by Mokhtari MB,et. al, mechanical ventilation came as a significant risk factor [36]. In a prospective cohort study by Karna P,et.al, from USA has shown that mechanical ventilation is a significant risk factor [32].

In the presentstudy anemia found to be significant risk factor. [ $\mathrm{p}=<0.001$ ] In another study by Rekha $\mathrm{S}$ et. al, [33] in 1996 anemia came as a significant risk factor. In a study done by LiLiu et. al, [39] from china, anemia was a significant risk factor.

In the present study there is a highly significant association between blood and blood products transfusion $[p=<0.001]$. In a study done in Brazil by Pinheiro AM et. al, [36] there was a significant association between blood transfusion and ROP $[p=0.022]$. In a study done in Egypt by Abdel H.A.A. Hakeemet. al, [37] there was a significant association between blood transfusion and ROP $[p=0.03]$. In a study done in Iran by Mojginbayat-Mokhtari et. al, [38] there was a significant association between blood transfusion and ROP.

In the present study there is a significant association between double volume exchange transfusion and ROP.
In a study done by Dutta $\mathrm{S}$ et.al, in 2004, there was a significant association between double volume exchange transfusion and ROP [35].

\section{Conclusion}

ROP is a disorder of developing retinal blood vessels in the premature infant retina. ROP is the commonest and more preventable form of blindness. During the study period of 2 years 200 babies were screened for ROP in which 27 were found to be positive. Our incidence rate is $13.5 \%$. ROP is found to be associated with the following risk factors in the present study Oxygen therapy, ventilation, anemia and exchange transfusion. Out of 27 positive babies for ROP 18 babies were $<1500 \mathrm{gm}$ and 9 babies were $>1500 \mathrm{gm}$. If we followed AAP guidelines we would have missed 9 babies. It suggests that we should screen large babies with risk factors.

\section{Funding: Nil, Conflict of interest: Nil Permission from IRB: Yes}

\section{References}

1. The Committee for the Classification of Retinopathy of Prematurity. An international classification of retinopathy of prematurity. Arch Ophthalmol. 1984; 102:1130-1134.

2. Terry, TL: Extreme prematurity and fibroblastic overgrowth of persistent vascular sheath behind each crystalline lens. I. Preliminary report, Am J Ophthalmol. 1942:25:203-204.

3. Gilbert C. Changing challenges in the control of blindness in children. Eye (Lond) 2007; 21: 1338-43.

4. Gilbert C. Retinopathy of prematurity: a global perspective of the epidemics, population of babies at risk and implications for control. Early Hum Dev 2008; $84: 77-82$.

5. Park JE, Park K. Preventive medicine in obstretics, paediatrics and geriatrics.In: Park JE, Park K (eds), Park's Textbook of Preventive and Social Medicine. New Delhi, Banarasidas Bahnot, 1991, pp.306-320.

6. Charan R, Dogra M R, Gupta A, Narang A. The incidence of retinopathy of prematurity in a neonatal care unit. Indian J Ophthalmol 1995; 43:123-6.

7. Global initiative for the elimination of avoidable 
blindness. Geneva, World Health Organization, 1998 (unpublished document WHO/PBL/97.61).

8. Foster A, Gilbert CE. Epidemiology of childhood blindness. Eye 1992; 6:173-6.

9. Coats DK, Aaron MM, Mohamed AH. Involution of retinopathy of prematurity after laser treatment: Factors associated with development of retinal detachment. Am J Ophthalmol. 2005; 140:214-22.

10. Terry, TL: Fibroblastic overgrowth of persistent tunica vasculosa lentis in premature infants. II. Report of cases-clinical aspects, Arch Ophthalmol. 1943: 29:36-53.

11. Quinn GE, Johnson L, Abbasi S. Onset' of retinopathy of prematurity as related topostnatal and postconceptual age. Br J Ophthalmol 1992b; 76: 284-8.

12. Fielder AR, Levene MI. Screening for retinopathy of prematurity. Arch Dis Child 1992; 67: 860-7.

13. Kinsey VE. Retrolental fibroplasia: cooperative study of retrolental fibroplasia and the use of oxygen. AMA Arch Ophthalmol. 1956 Oct; 56(4):481-543.

14. Lanman, IT, Guy, LP, and Dancis, J: Retziolental fibroplasia and oxygen therapy, JAMA 1954: 155:223226.

15. Patz, A, Eastham, A, Higginbotham, DH, and Kleh, $\mathrm{T}$ : Oxygen studies in retrolental fibroplasia. II. The production of the microscopic changes of retrolental fibroplasia in experimental animals, Am J Ophthalmol. 1953:36:1511-1522.

16. Provis IM. Development of the primate retinal vasculature. Prog Retin Eye Res. 2001 Nov; 20(6):799821.

17. Sellheyer K, Spitznas M. Morphology of the developing choroidal vasculature in the human fetus. Graefe's Arch Clin Exp Ophthalmol 1988; 226: 461-7.

18. Ashton N. Retinal angiogenesis in the human embryo. Br Med Bull 1970; 26: 103-6.

19. Keshet E. Preventing pathological regression of blood vessels. J Clin Invest 2003; 112: 27-9.
20. Chaudhari S, Patwardhan V, Vaidya U, Kadam S, Kamat A. Retinopathy of prematurity in a tertiary care center--incidence, risk factors and outcome. Indian Pediatr 2009; 46:219-24.

21. Aggarwal R, Deorari AK, Azad RV, et al. Changing profile of retinopathy of prematurity. J Trop Pediatr 2002; 48:239-42.

22. Varughese S, Jain S, Gupta N, Singh S, Tyagi V, Puliyel JM. Magnitude of the problem of retinopathy of prematurity. Experience in a large maternity unit with a medium size level-3 nursery. Indian $\mathbf{J}$ Ophthalmol 2001; 49:187-8.

23. Kinsey VE, Arnold HI, Kalina RE, et al. Pa02 levels and retrolental fibroplasia: a report of the co-operative study. Pediatrics 1977; 60: 655-68.

24. Fielder AR, Levene MI. Screening for retinopathy of prematurity. Arch Dis Child 1992; 67: 860-7.

25. Schaffer DB, Palmer EA, Plotsky DF, et al, on behalf of the Cryotherapy for Retinopathy of Prematurity Cooperative Group. Prognostic, factors in the natural course of retinopathy of prematurity: Ophthalmology 1993; 100: 230-7.

26. Fielder AR, Shaw DE, Robinson J, et al. Natural history of retinopathy of prematurity: a prospective study. Eye 1992b; 6: 233-42.

27. Chaudhari S, Patwardhan V, Vaidya U, Kadam S, Kamat A. Retinopathy of prematurity in a tertiary care center--incidence, risk factors and outcome. Indian Pediatr 2009; 46:219-24.

28. Saito Y, Omoto T, Cho Y, et al. The progression of retinopathy of prematurity and fluctuation in blood gas tension. Graefe's Arch Clin Exp Ophthalrnol 1993; 231: 151-6.

29. Cunningham S, Fleck BWElton RA, et al. Transcutaneous oxygen levels in retinopathy of prematurity. Lancet, 1995; 346: 1464-5.

30. York JR, Landers S, Kirby RS, et al. Arterial oxygen fluctuation and retinopathy of prematurity in very-low-birth-weight infants. J Perinatology 2004; 24 : 82-7. 
31. Ng YK, Fielder AR, Levene MI, et al. Are severe retinopathy of prematurity and severe pe-Fiventricular leucomalacia both ischaemic insults? Br J Ophthalmol 1989; 73: 111-14.

32. Ashton N, Henkind P. Experimental occlusion of retinal arterioles. Br J Ophthalmol 1965; 49: 225-34.

33. Rekha S, Battu RR. Retinopathy of prematurity: incidence and risk factors. Indian Pediatr 1996; 33:9991003.

34. Gupta VP, Dhaliwal U, Sharma R, Gupta P, Rohatgi J. Retinopathy of prematurity risk factors. Indian $\mathbf{J}$ Pediatr 2004; 71:887-92.

35. Dutta S, Narang S, Narang A, Dogra M, Gupta A. Risk factors of threshold retinopathy of prematurity. Indian Pediatr 2004; 41:665-71.
36. Pinheiro AM,Silva WA.Incidence and risk factors of retinopathy of prematurity in university hospital Onfore Lopes, Brazil. Arq Bras Ophtalmol. 2009; 72(4):451-6.

37. Hakeem AHAA, Mohammed GB, Otham M. Retinopathy of prematurity. J Clin Neonatol. 2012 AprJun; 1(2): 76-81

38. Karna P, Muttineni J, Anjell L, Karmaus W. Retinopathy of prematurity and risk factors:a prospective cohort study. BMC Pediatrics 2005, 5:18.

39. Liu L, Tian T, Zheng CX,Ileana v,Loana A, Tatiana C, Oana R.Risk factors and laser therapy for retinopathy of prematurity in neonatal intensive care unit. World $\mathrm{J}$ Pediatr 2009; 5(4):304-307.

\section{How to cite this article?}

Reddy B, Doddamani R.M, Koujalagi M.B, Guruprasad G, Ashwini R.C, Aradya G.H, Raghoji C. Retinopathy of prematurity in a tertiary care hospital: incidence and risk factors. Int $J$ Pediatr Res.2016;3(5):364370.doi:10.17511/ijpr.2016.i05.17 